\title{
Optical Fiber Distributed Sensing Structural Health Monitoring (SHM) Strain Measurements Taken During Cryotank Y-Joint Test Article Load Cycling at Liquid Helium Temperatures
}

\author{
Sidney G. Allison, William H. Prosser, David A. Hare, Thomas C. Moore and W. Scott Kenner \\ NASA Langley Research Center, Hampton, VA, USA 23681
}

\begin{abstract}
This paper outlines cryogenic Y-joint testing at Langley Research Center (LaRC) to validate the performance of optical fiber Bragg grating strain sensors for measuring strain at liquid helium temperature $\left(-240^{\circ} \mathrm{C}\right)$. This testing also verified survivability of fiber sensors after experiencing 10 thermal cool-down, warm-up cycles and 400 limit load cycles. Graphite composite skins bonded to a honeycomb substrate in a sandwich configuration comprised the Y-joint specimens. To enable SHM of composite cryotanks for consideration to future spacecraft, a light-weight, durable monitoring technology is needed. The fiber optic distributed Bragg grating strain sensing system developed at LaRC is a viable substitute for conventional strain gauges which are not practical for SHM. This distributed sensing technology uses an Optical Frequency Domain Reflectometer (OFDR). This measurement approach has the advantage that it can measure hundreds of Bragg grating sensors per fiber and the sensors are all written at one frequency, greatly simplifying fiber manufacturing. Fiber optic strain measurements compared well to conventional strain gauge measurements obtained during these tests. These results demonstrated a high potential for a successful implementation of a SHM system incorporating LaRC's fiber optic sensing system on the composite cryotank and other future cryogenic applications.
\end{abstract}

Keywords: Fiber optic sensing, optical frequency domain reflectometry, Bragg gratings, cryogenic fuel tank, liquid Helium

\section{INTRODUCTION}

Optical fiber Bragg grating (FBG) sensors can be used to measure strain and other parameters such as temperature in numerous applications ${ }^{1-9}$. Distributed FBG sensing is particularly beneficial for structural health monitoring (SHM) applications such as Integrated Vehicle Health Management (IVHM) of aerospace vehicles. Numerous references to fiber grating developmental work can be found in a review of fiber grating sensors by Kersey et al. ${ }^{10}$ A grating-based system developed at NASA Langley ${ }^{6}$ is ideal for spaceflight because it has the ability to multiplex up to thousands of Bragg gratings in a single fiber. ${ }^{9}$ The system is based on the principle of optical frequency domain reflectometry (OFDR $)^{5}$ and offers the advantage that all of the gratings are of nominally the same wavelength. Writing gratings at the same wavelength greatly simplifies manufacturing of the sensing fiber. Typical Bragg grating readout systems require gratings with much higher reflectivities. However, the OFDR employs a coherent detection scheme and is capable of reading out very low reflectivity gratings. This allows the recording and analysis of strain or temperature from a large number of gratings in a single fiber.

Prior applications ${ }^{3}$ have demonstrated use of fiber optic sensors at ambient temperatures. One concern of optical fiber sensors has been that of suitability for use at cryogenic temperatures such as in cryogenic fuel tanks in aerospace vehicles. Fiber optic sensors would be particularly advantageous in cryogenic fuel tanks because they would not pose an electrical arcing ignition source as failed strain gauges or other electronic sensors might. In addition, OFDR technology offers considerable weight savings since it can provide a large number of strain measurements per fiber whereas each conventional strain gauge requires individual electrical wiring. The Y-joint represents a critical region of composite cryotanks ${ }^{11}$ being developed for the Next Generation Launch Technology (NGLT) Program and offered a platform for demonstrating OFDR technology at liquid helium temperature of $-240^{\circ} \mathrm{C}$. A series of Y-joint test articles was provided by Northrop Grumman Corporation (NGC) under contract to NASA as part of the Next Generation Launch Technology (NGLT) program for structural and sensor validation. This paper describes the results from the Yjoint Structural Health Monitoring (SHM) tests on a Y-joint test article at liquid helium temperature conducted at 
NASA Langley Research Center ${ }^{12-13}$. These tests were performed to investigate the functionality, durability, and reliability of fiber optic Bragg grating sensors at cryogenic temperatures down to $-240^{\circ} \mathrm{C}$. Results from these tests were used to assess the feasibility of integrating fiber optic sensors as structural health monitoring sensors for future cryotank applications.

\section{Y-JOINT TEST SPECIMEN AND INSTRUMENTATION}

\subsection{Y-joint test article}

The Y-joint test article consists of outer skirt and inner dome graphite epoxy composite skin layers bonded to a honeycomb substrate in a sandwich configuration as shown in Figure 1. The Y-joint measures $198 \mathrm{~cm}$ in length, $15 \mathrm{~cm}$ in width and 4.45 to $15 \mathrm{~cm}$ in depth. The inner dome layer represents the part of the tank skin exposed directly to the liquid Hydrogen fuel. The skirt portion provides means of mounting the tank to the launch vehicle and is not directly exposed to the cryogenic temperatures. The Y-joint was instrumented with 38 low temperature strain gauges and 30 thermocouples before strain-sensing optical fiber was installed. Strain gauge pairs were located at stations along the Yjoint test article. Strain gauges 1 and 2 measured strain at one station, strain gauges 3 and 4 at another station and so on.

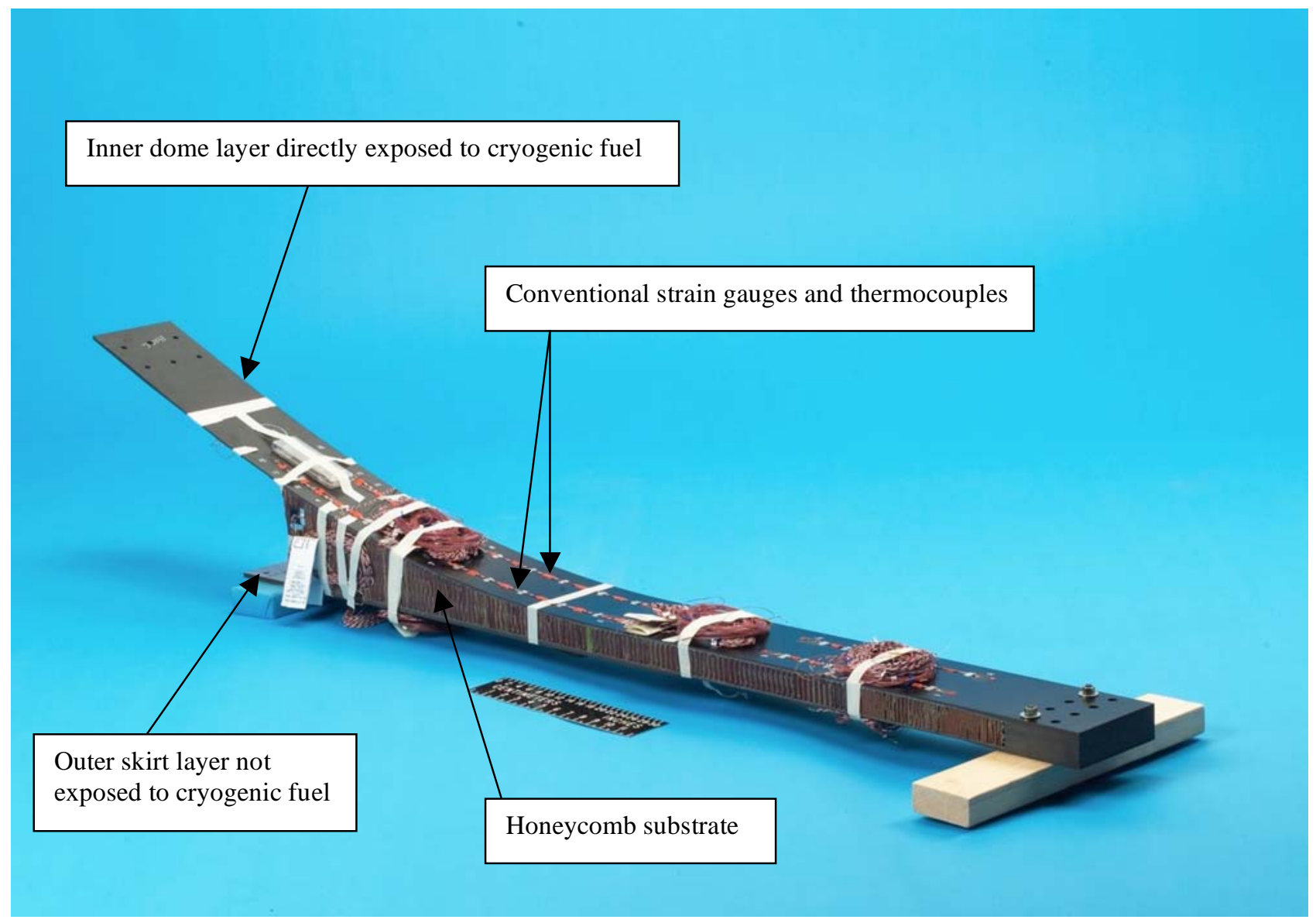

Figure 1. Y-joint test article instrumented with conventional strain gauges and thermocouples before installing strain-sensing fiber.

\subsection{Optical fibers with Bragg grating strain sensors}

The single-mode optical fiber used in this experiment was drawn by LaRC using a preform similar to that for making SMF 28 fiber, but having higher germanium doping. This resulted in fiber having higher numerical aperture and 
exhibiting lower bend loss than SMF 28 fiber would possess. The fiber contained Bragg gratings written at $1550.2 \mathrm{~nm}$ during the draw process and each FBG had a low reflectivity estimated at $0.004 \%$. Typical Bragg grating measurement systems require gratings with much higher reflectivities. Low reflectivity Bragg gratings were used in this experiment because the OFDR system employs a coherent detection scheme and is designed with a high spatial resolution for reading multiple equal wavelength gratings with very low reflectivity. In fact, the OFDR can read hundreds of lowreflectivity gratings in a single fiber.

As the fiber was being drawn by LaRC, gratings were written $10 \mathrm{~cm}$ apart on the bare fiber as it emerged from the preform melt furnace of the draw tower. As the fiber with gratings continued moving down the draw tower, it was coated with two layers of polyimide which are cured by infrared ovens before the finished fiber was spooled and ready for use. The finished fiber had a $0.152 \mathrm{~mm}$ overall diameter including the coating. The role of the coating is to protect the fiber. ${ }^{14-15}$ Bare or uncoated fibers are exceedingly weak due to the ease of extrinsic flaw formation by surface abrasion and attack from moisture and other hostile chemicals in the environment.

A patch cord was fusion spliced to one end of each Y-joint strain measurement fibers for connecting to the OFDR system. Fusion splice protectors were kept outside of the cryogenic environment for the Y-joint tests because they had been found in previous work to break the optical fiber and not survive exposure to cryogenic environments.

MicroLumen $0.5334 \mathrm{~cm}$ outside diameter polyimide tubing inside a sheath of woven fiberglass tubing protects the portion of measurement fiber from the fusion splice protector to the Y-joint test article. A section of this sheathing near the end where the measurement fiber exits the sheathing at the Y-joint was impregnated with RTV-159 adhesive to bond the sheathing to the polyimide tubing and provide stiffening to help facilitate bonding the end of the sheathing to the Y-joint test article as will be described in section 2.3.

\subsection{Bonding strain measurement fibers to $\mathrm{Y}$-joint test article}

The Y-joint was instrumented with a total of 6 optical fibers. Fibers 1,2 and 3 were bonded to the outer skirt of the Yjoint along the length but because they are not exposed to liquid helium temperatures they are of less interest and not reported on herein. Fibers 4, 5 and 6 were bonded on the dome side along the length of the Y-joint element as seen in Figure 2. The dome side of the Y-joint was in contact with the cold plate described in section 3.1 of this paper and includes the fibers of interest because it was subjected to temperatures of $-240^{\circ} \mathrm{C}$ and below. Each dome fiber ranged in length from approximately $160 \mathrm{~cm}$ to $180 \mathrm{~cm}$ while the skirt fibers were approximately $140 \mathrm{~cm}$ long. Depending on the overall length of the fiber, each fiber contains 14-18 fiber Bragg grating strain sensors, each equally spaced $10 \mathrm{~cm}$ apart. Each Bragg grating sensor had an active gauge length of $5 \mathrm{~mm}$. The locations of the fiber Bragg gratings on fibers 4 and 5 in relation to the conventional foil strain gauges are shown in Figure 3. In Figure 3, the fiber Bragg gratings are indicated with standard numerals and the strain gauges are represented with an "S" prefix. Results are not presented for fiber 6 because it broke due to coming into contact with a sharp edge on the cold plate during testing. Failure of Fiber 6 was not due to exposure to the cryogenic testing. As can be seen in Figure 3, the fiber Bragg grating sensors are not colocated exactly next to the conventional strain gauges and this mismatch likely contributed to differences in strain readings of the gratings vs. strain gauges.

Techniques and cements used to bond conventional strain gages were utilized for securing optical fibers ${ }^{16}$ to the Y-joint test articles. Micro-Measurements M-Bond 610 adhesive was chosen because of its suitability for use at cryogenic and elevated temperatures, and because it produces a low creep installation. The following technique was developed for installing fibers to the $\mathrm{Y}$ joints. The substrate area that the fiber was to be bonded to was cleaned with a degreaser solvent such as Hypersolve or Ensolve. The surface to be instrumented was abraded by micro-sandblasting with 50micron aluminum oxide blasting media using a micro sand blaster such as a SS. White Microsandblaster until the sheen is removed and the surface is lightly abraded. Sanding the surface with 320 grit silicon carbide sand paper was an alternate means that could have been used to abrade the surface. Once abraded, adhesive should be applied as soon as possible, minimizing time for surface oxidation and contamination. After the abrading, the surface was cleaned with one of the appropriate degreaser solvents mentioned above. Kapton tape was used to mask off a track where the fiber was to be installed so that a base coat of M-Bond 610 adhesive could be applied. Wearing cotton gloves helped keep the area free of contaminates such as oils from hands. Using an airbrush, a $.0254 \mathrm{~mm}$ to $.0508 \mathrm{~mm}$ thick base coat of the M-Bond 610 adhesive was applied to the masked area. The base coat protects the area from oxidizing and fills any 
voids in the specimen surface for the fiber installation. The adhesive was allowed to cure for one hour at room temperature before the tape was removed. The base coat was then cured at $107^{\circ} \mathrm{C}$ for 4 hours in a convection oven.

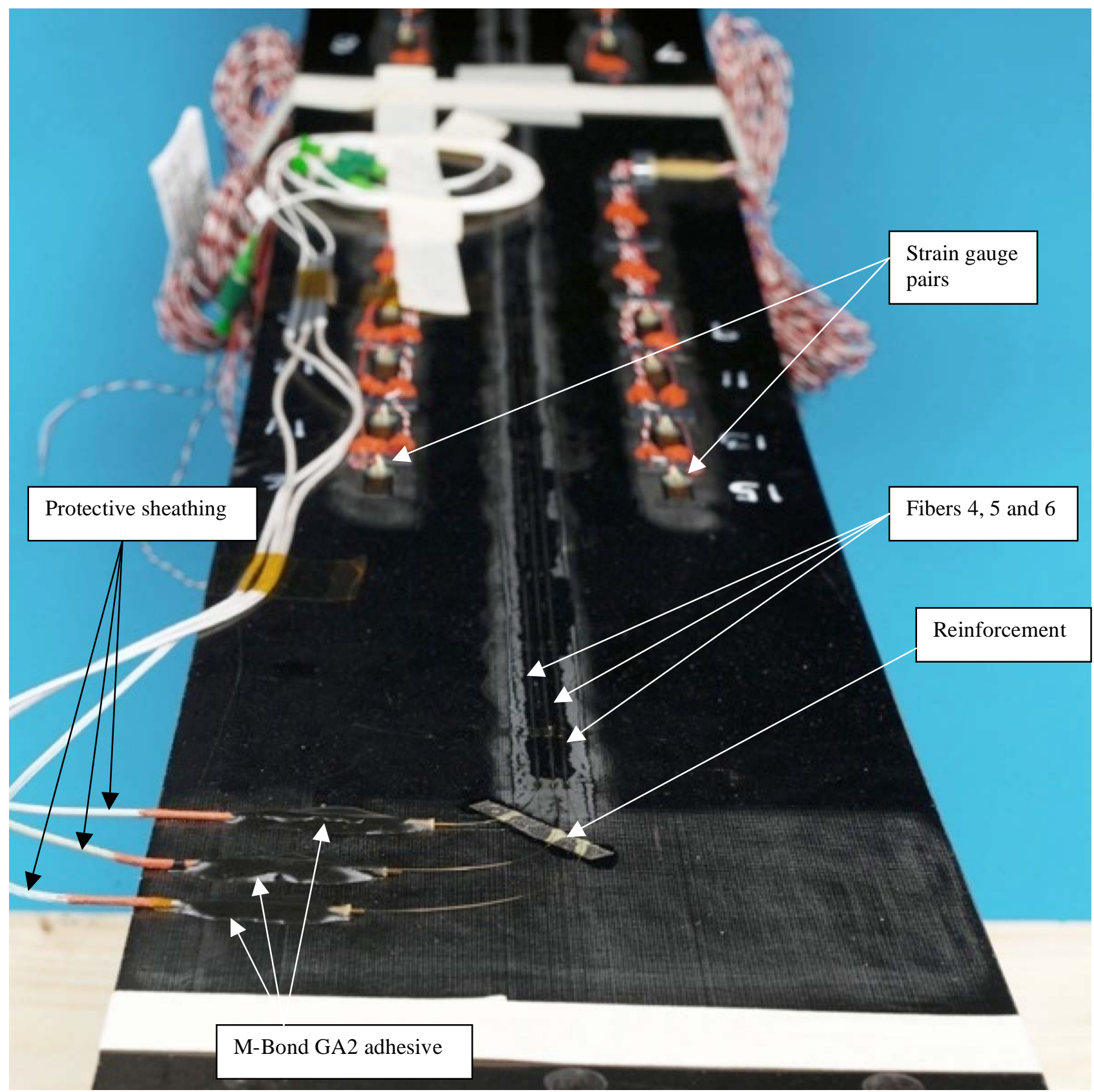

Figure 2. Three optical strain-sensing fibers bonded to dome side of Y-joint test article 


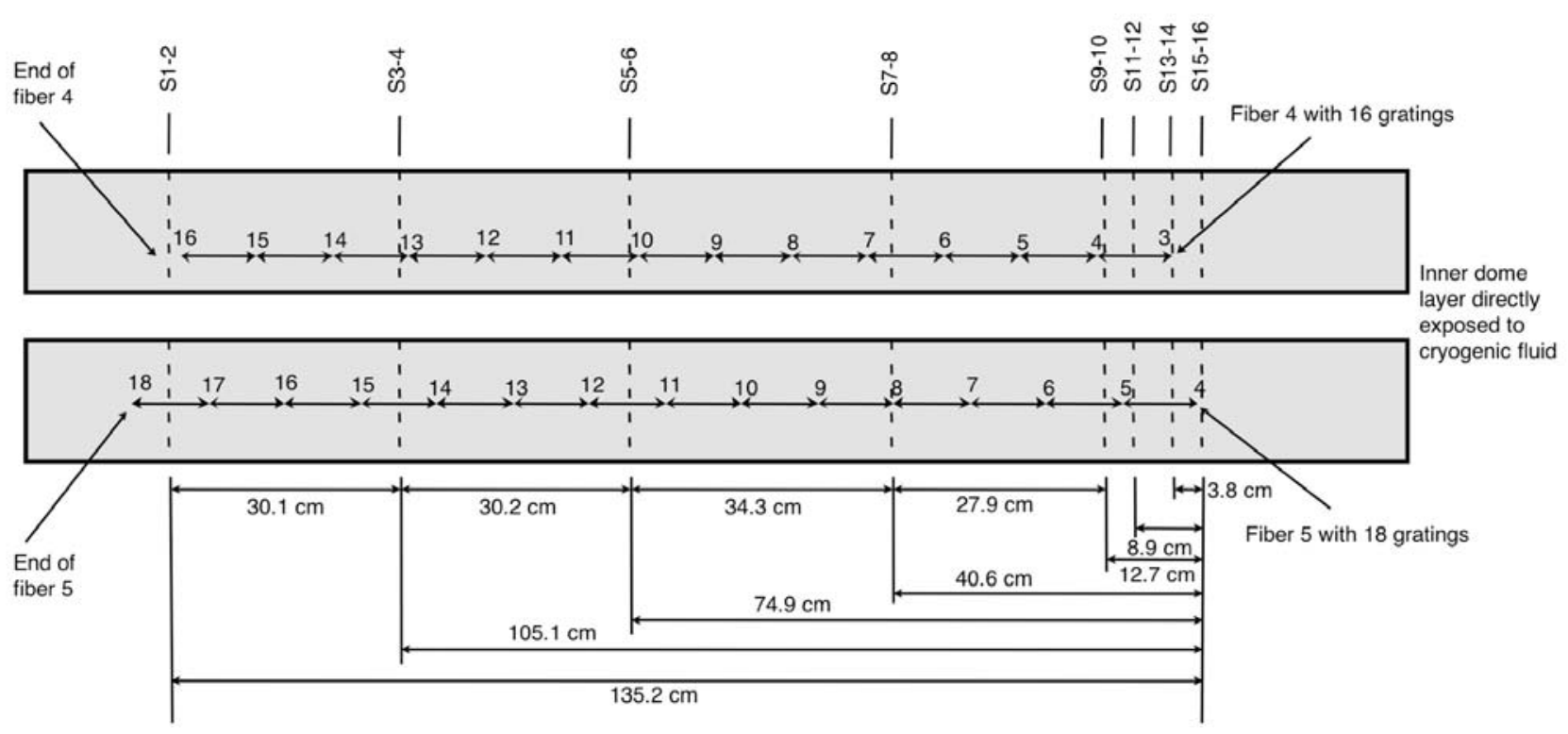

Figure 3. Fiber Bragg gratings and strain gauge locations

After the Y-joint test article returned to room temperature, the base coat was lightly micro sandblast using 50-micron aluminum oxide sand. The sand was cleaned from the surface using a brush. The surface was wiped with a tissue saturated with 200 proof grain alcohol. Any lint was removed with clean dry shop air. The fiber was secured to the Yjoint using pieces of Kapton tape cut into $2.54 \mathrm{~mm}$ x $5.08 \mathrm{~mm}$ strips. The fiber was cleaned with 200 proof grain alcohol and cotton swabs as it was secured to the Y-joint. The strips of tape were applied every 2.54-5.08 $\mathrm{cm}$ taking care not to tape over any of the gratings. After the fiber was taped in place, a coat of M-Bond 610 adhesive was applied to the fiber-surface interface segments between the pieces of tape using a thin artist brush and a dispensing system such as Engineered Fluid Dispensing system. Care was taken not to over saturate the fiber with adhesive, otherwise the adhesive might have wicked under the Kapton tape and caused voids in the bond. The adhesive was allowed to cure for one hour at room temperature to reduce the amount of bubbles along the length of the fiber. The Y-joint test article was then cured at $107^{\circ} \mathrm{C}$ for 4 hours in the convection oven.

The Y-joint was allowed to return to room temperature in order to back-fill where the pieces of tape were and reinforce the fiber ends. The existing pieces of Kapton tape that were holding the fibers in place were removed. The un-bonded sections of the fiber were cleaned using 200 proof grain alcohol. M-Bond 610 adhesive was applied to the unsecured portions of fiber using the technique described above. Areas where the fiber transitioned from un-bonded to bonded were weak because the adhesive tended to wick away along the fiber leaving a very thin coating where the fiber exited the Y-joint surface. To reinforce these areas, two pieces of paper such as lens cleaning paper were saturated with MBond 610 and placed at the start and end of each fiber to form dams as seen in Figure 2. This reinforcement prevented the fiber from initiating a run in which the fiber might have started tearing away from the surface. The M-Bond 610 adhesive was allowed to cure at room temperature for one hour. The Y-joint test article was then cured at $107^{\circ} \mathrm{C}$ for 4 hours in the convection oven. Following this cure bake, the Y-joint cooled to room temperature and the instillation was inspected. The adhesive was then post-cured at $107^{\circ} \mathrm{C}$ for 20 hours to stabilize the M-Bond 610 adhesive. Following this post-cure bake, the Y-joint cooled to room temperature. The stiffened section of sheathing described in section 2.2 was secured to the surface, just before the fiber exits the sheathing, using Micro-Measurements M-Bond GA2 strain gauge adhesive as shown in Figure 2, curing in 6 hours at room temperature. 


\subsection{OFDR distributed fiber optic sensing system}

The fiber optic distributed sensing system shown in Figure 4 had four data acquisition channels available so only 4 of the 6 fibers were monitored during the test (all 3 fibers on the dome side and 1 center fiber, fiber 2, on the skirt side).

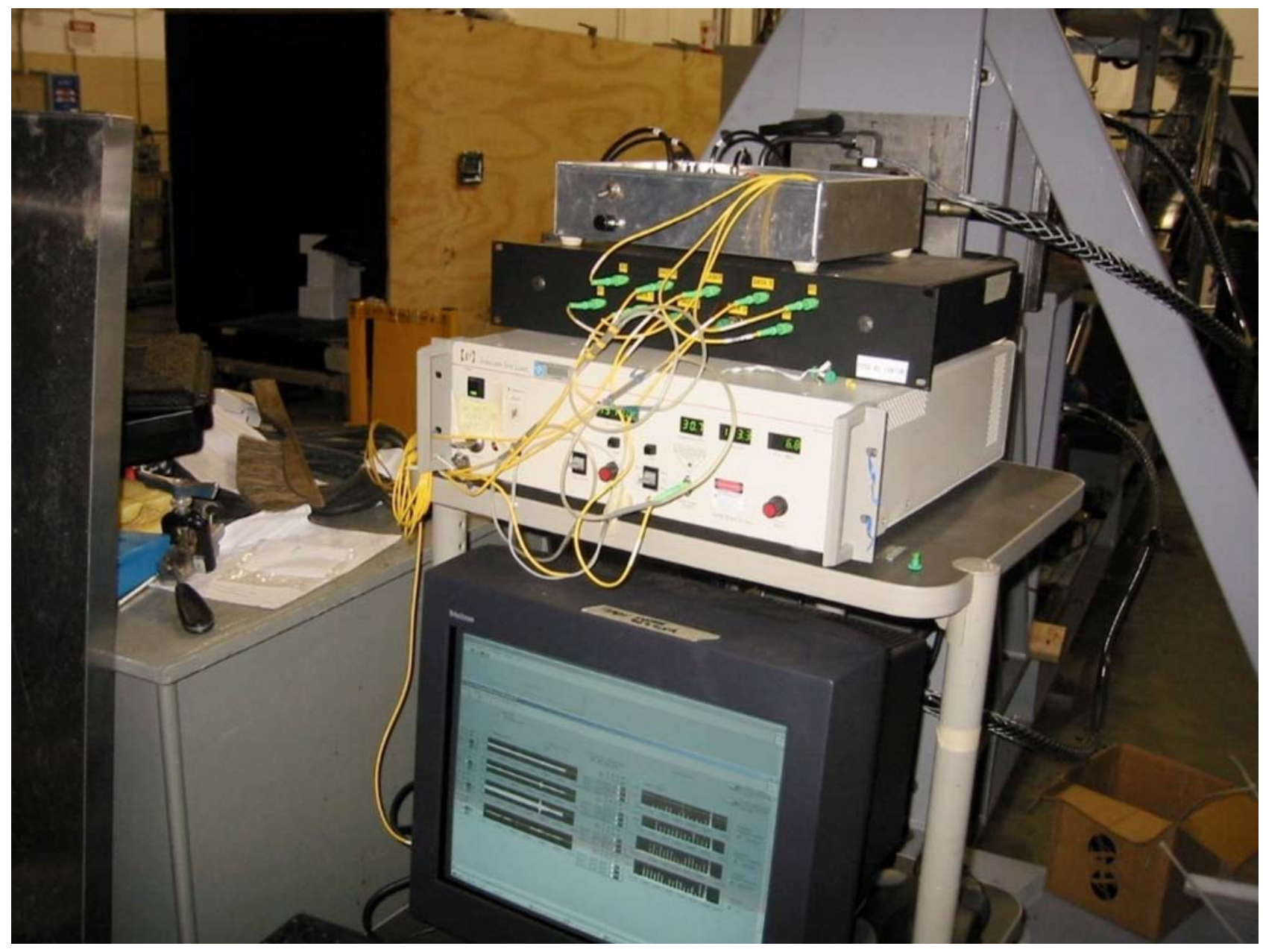

Figure 4. Distributed Fiber Optic Sensing System with four channels.

\section{TEST SETUP}

\subsection{Cold plate}

The cold plate is an aluminum fixture having a top surface conformed to the shape of the dome side of the Y-joint test article to allow loading the dome skin in tension. The cold plate also provides means for cooling the Y-joint dome skin using cryogenic liquids. Figure 5 shows the cold plate containing copper tubing seen entering and exiting through the sides. Liquid Nitrogen is circulated through this tubing for pre-cooling to reduce liquid Helium consumption. In addition, spray bars made of copper tubing with small spray holes were recessed into 3 grooves running the length of the cold plate for spraying liquid Helium onto the dome side of the Y-joint test article to complete cool down to $-240^{\circ} \mathrm{C}$. 


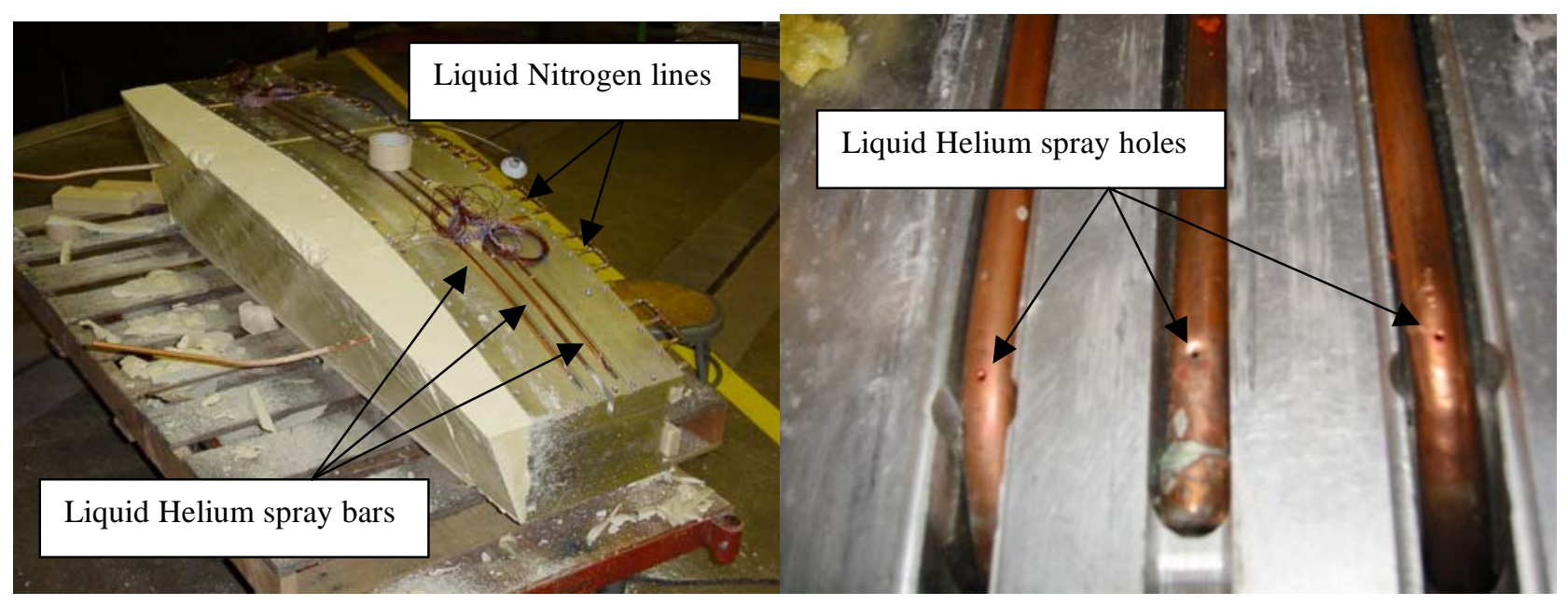

Figure 5. Cold plate with surface contoured to the Y-joint shape. Copper lines circulate liquid nitrogen for pre-cooling. Copper spray bars in three grooves run the length of the cold plate and spray liquid helium onto the $\mathrm{Y}$-joint test article.

\subsection{Load frame test facility}

Figure 6 shows the Y-joint test facility designed to subject the Y-joint test article to cryogenic temperatures and apply loading. The cold plate is installed in the load frame and the Y-joint is placed on the cold plate. Both ends of the Yjoint dome skin are bolted to hydraulic actuators for applying tensile load. After installation of the Y-joint onto the cold plate, insulating foam was sprayed onto the test specimen to help contain the liquid cryogen and minimize thermal losses during cooling process and subsequent cycling. This facility is capable of applying tensile load to the Y-joint dome skin while simultaneously applying compressive load to the skirt for structural load bearing tests. For testing the fiber sensors, tension was applied to the dome skin but no load was applied to the skirt.

Figure 7 shows the installed $\mathrm{Y}$-joint test article being cooled in the load frame test facility where load is cycled at cryogenic temperature. Liquid Helium sprayed onto the $\mathrm{Y}$-joint test article dome surface during cryogenic testing is released into the atmosphere.

\subsection{Test procedure}

The fiber optic validation approach consisted of conducting 10 thermal cycles from room temperature to $-240^{\circ} \mathrm{C}$ as read by thermocouples on the dome side of the Y-joint test article and applying 40 mechanical loading cycles each time the Y-joint reached $-240^{\circ} \mathrm{C}$. Each mechanical cycle consisted of loading the dome section in tension to the $100 \%$ limit load of 81425 N. Fiber optic strain data was recorded during load ramp holds at $0 \%, 50 \%$, and $100 \%$ of the limit load both during loading and unloading. Five of the six fibers survived throughout the total 400 cycles. Fiber 6 failed during load cycle 127 because the fiber came into physical contact with a grooved edge in the cold plate during cycling. The fiber failure was the result of slight misalignment between the Y-joint test article and the cold plate and should not be attributed to fiber survivability at cryogenic temperatures. 


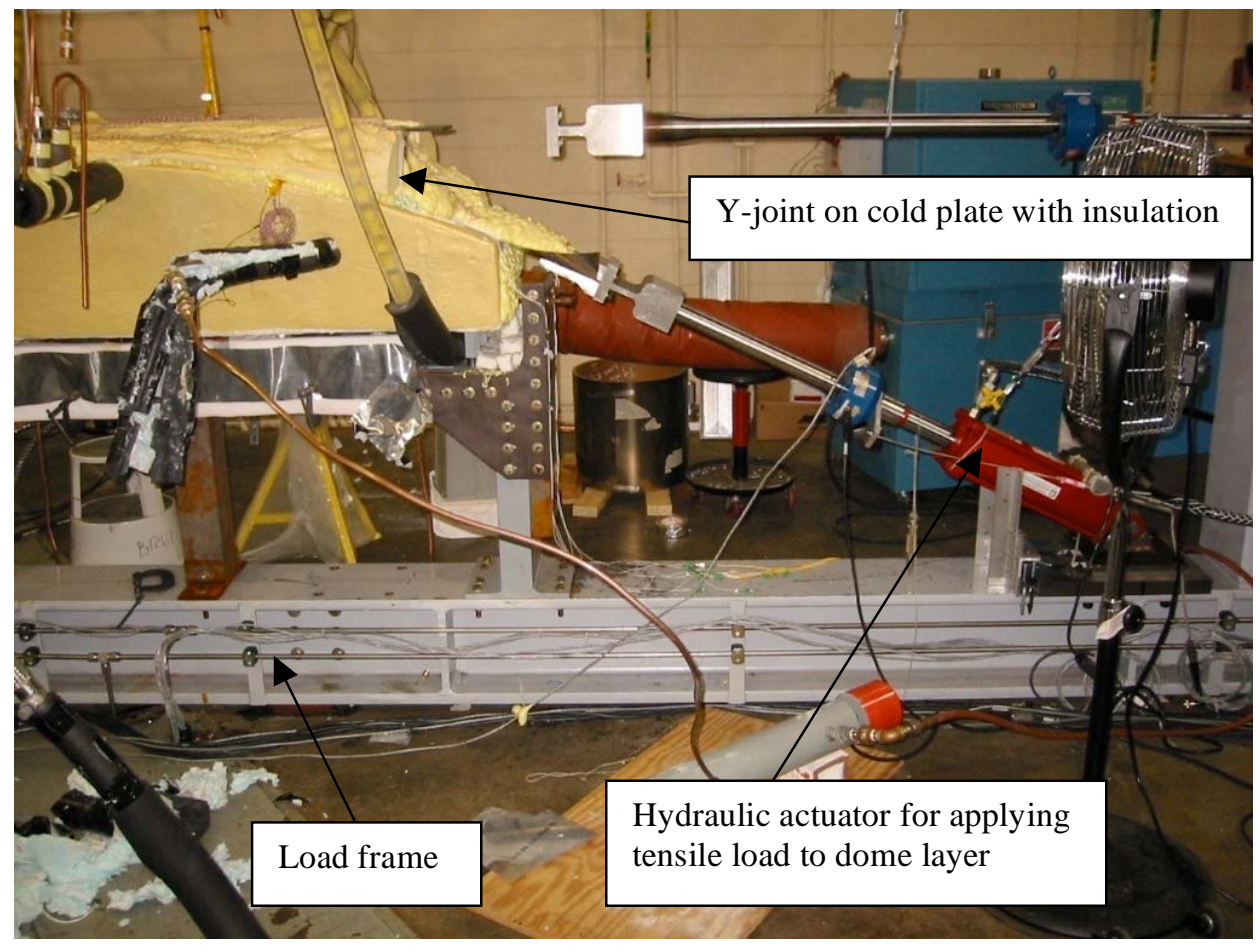

Figure 6. Y-Joint Test Facility with cold plate installed in load frame and test article installed on cold plate. The Y-joint is attached to hydraulic loading actuators at both ends for applying tensile load. Thermal insulation is added.

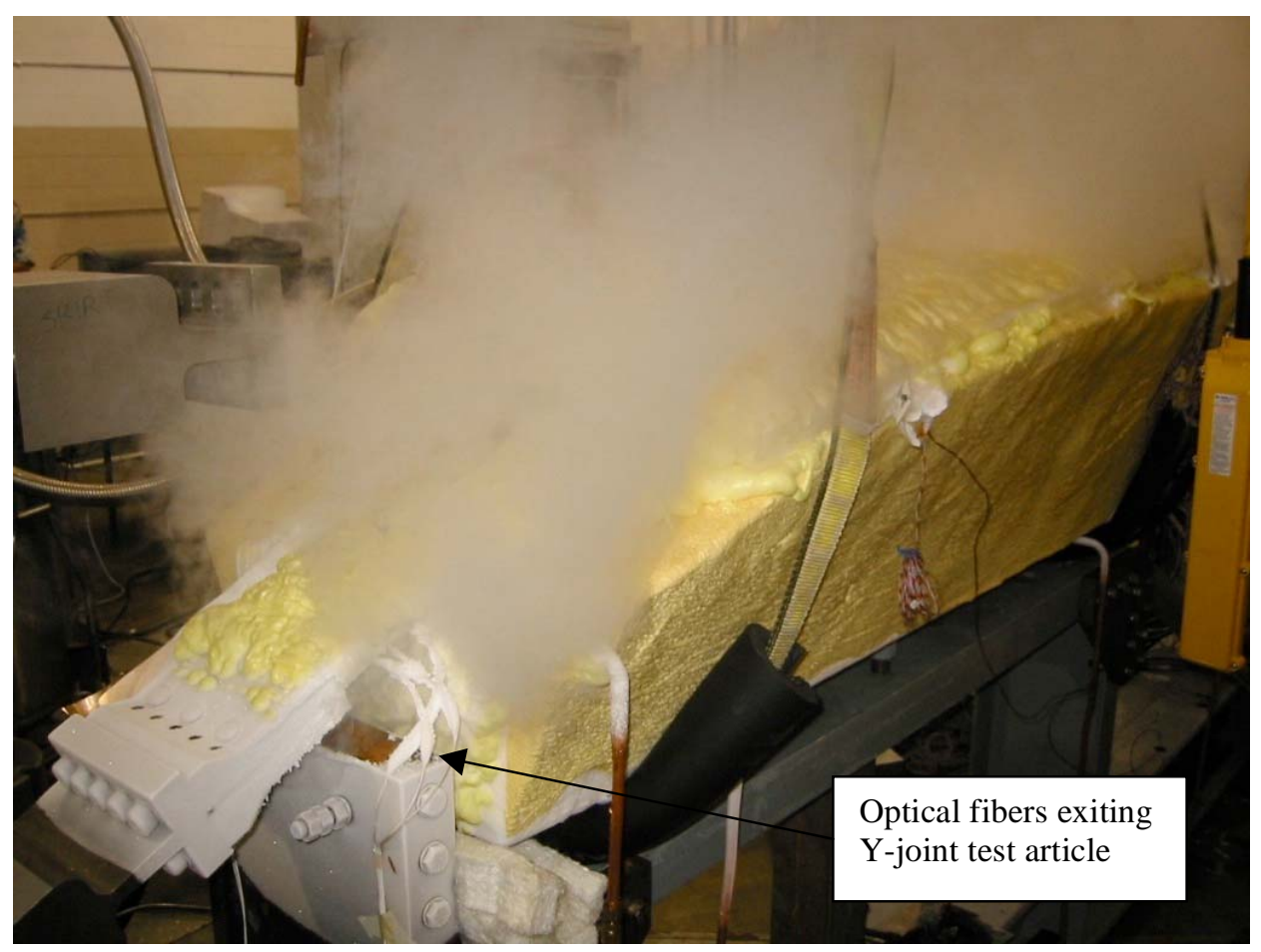

Figure 7. Installed Y-joint test article undergoing cryogenic cooling. Liquid Helium is sprayed onto the Y-joint dome surface and released to the atmosphere. 


\section{TEST RESULTS}

Strain data was taken for the 40 load cycles during the $-240^{\circ} \mathrm{C}$ portion of each of the 10 thermal cycles. Results presented here are for the $400^{\text {th }}$ load cycle occurring at the end of the $10^{\text {th }}$ thermal cycle. This result demonstrates that the fiber Bragg grating sensors survived the complete test sequence. Analysis of fiber optic and strain gauge data involved defining the initial strain to be zero before beginning load cycle 400 and plotting the change in strain during the load cycle. The graph in Figure 8 of Load percentage vs. Microstrain shows good agreement between strain gauge 3 , grating 13 on fiber 4 and grating 14 on fiber 5. Figure 9 shows good agreement between strain gauge 11, grating 4 on fiber 4 and grating 5 on fiber 5. The remaining gratings bonded to the Y-joint test article exhibited similar agreement with nearby conventional strain gauges. Finite element method (FEM) analysis reported elsewhere ${ }^{12}$ was also performed and agreed reasonably well with strain gauge and fiber optic strain measurements.

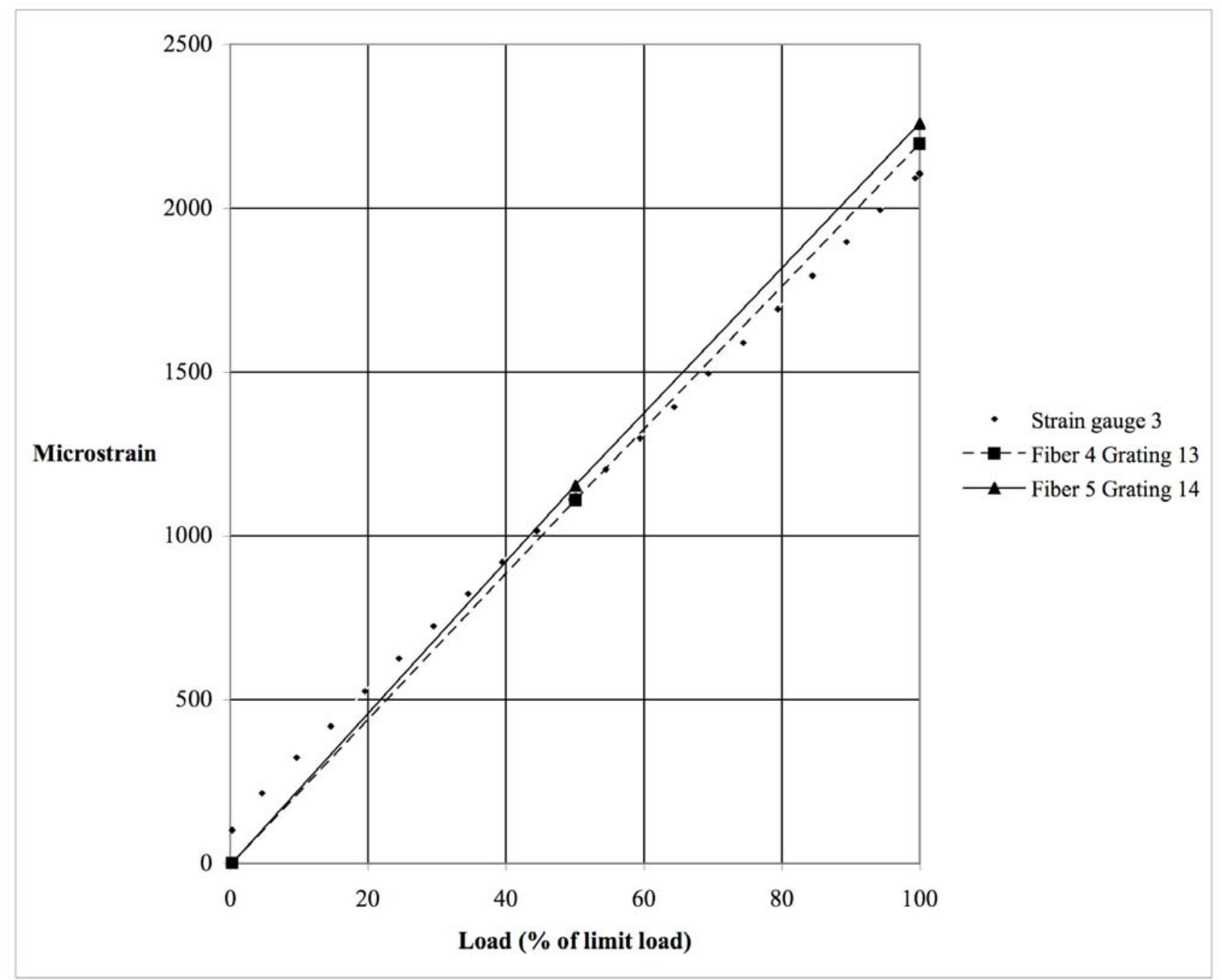

Figure 8. Comparison of strain measured by strain gauge 3 to strain measured by grating 13 in fiber 4 and grating 14 in fiber 5 during final load cycle of test series at $-240^{\circ} \mathrm{C}$. Fiber optic measurements were taken during $0 \%, 50 \%$ and $100 \%$ load holds during loading, whereas strain gauge data was taken continuously. 


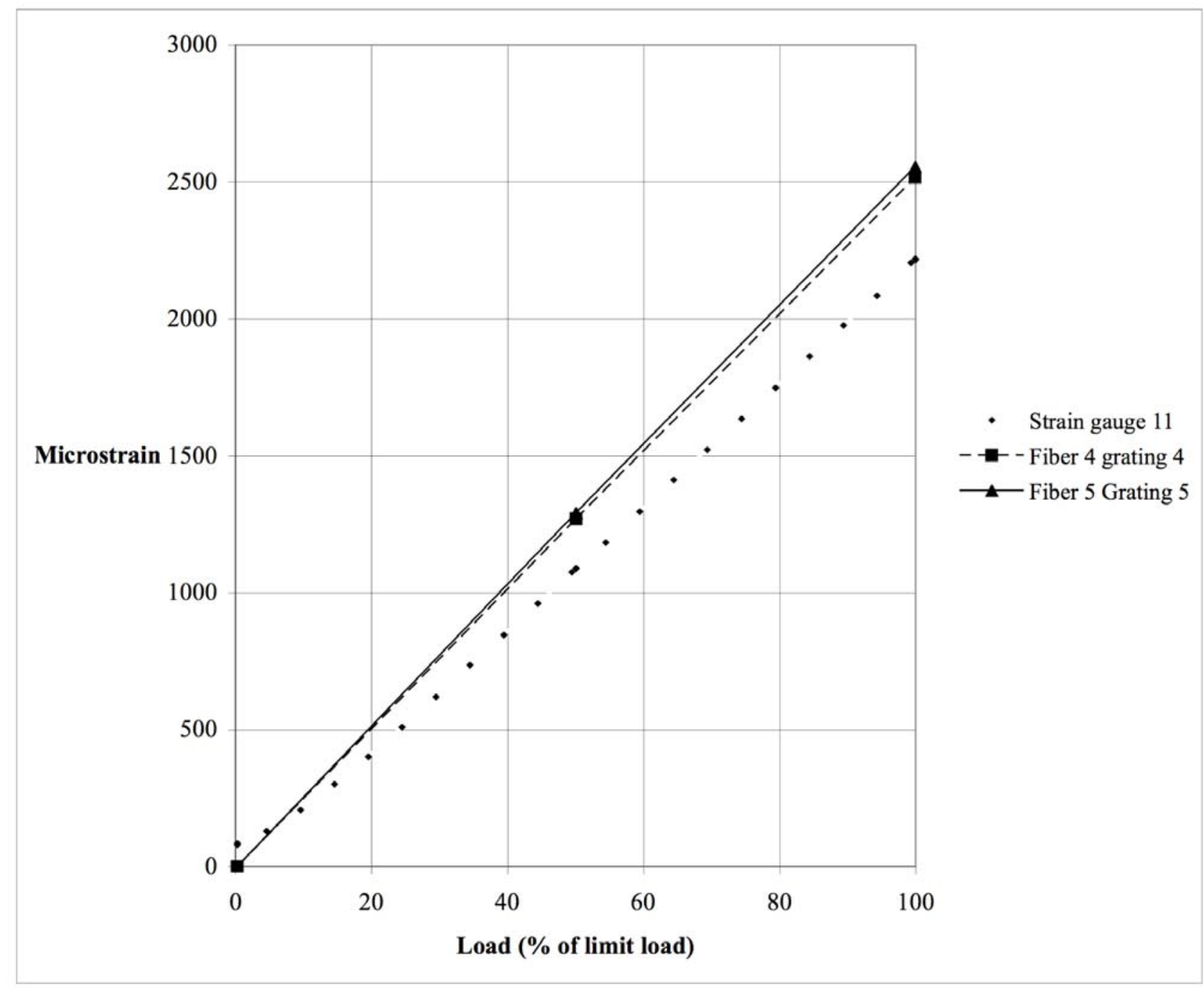

Figure 9. Comparison of strain measured by strain gauge 11 to strain measured by grating 4 in fiber 4 and grating 5 in fiber 5 during final load cycle of test series at $-240^{\circ} \mathrm{C}$. Fiber optic measurements were taken during $0 \%, 50 \%$ and $100 \%$ load holds during loading, whereas strain gauge data was taken continuously.

Differences between the fiber optic strains and the conventional strain gauge readings can be attributed to the Bragg gratings not being co-located exactly next to the strain gauges. Differences can also arise because of the strain-optic coefficient the OFDR system used and small temperature variations between the fiber optic sensors and thermocouples due to not being co-located, even though the tests were done as close to steady state as possible. The OFDR calculates strain changes from measured wavelength shifts using the well-known model ${ }^{17}$ for Bragg gratings:

$$
\Delta \lambda / \lambda=\mathrm{K} \varepsilon+\xi \Delta \mathrm{T}
$$

where $\Delta \lambda / \lambda$ is the normalized wavelength shift, $\mathrm{K}$ is the strain-optic coefficient, $\varepsilon$ is strain in the fiber grating, $\xi$ is the thermo-optic coefficient and $\Delta \mathrm{T}$ is temperature change. Although small temperature changes may have occurred, results reported here assumed the temperature remained at a constant $-240^{\circ} \mathrm{C}$ so that the thermal sensitivity term was assumed to drop out of the equation, leaving only the strain term. Equation (1) can be re-written:

$$
\varepsilon=(\Delta \lambda / \lambda) / K
$$


Software in the OFDR system used for these measurements is programmed with a strain-optic coefficient of 0.75 , therefore strains were calculated using this value of $\mathrm{K}$. However, the value of $\mathrm{K}$ can vary depending on the application as reported elsewhere. ${ }^{10,15,18}$ Calibration to determine the exact value of this strain-optic coefficient for this application was not performed and could account for differences between strain gauge and Bragg grating strains such as those in Figures 8 and 9.

\section{CONCLUSIONS}

Y-joint test articles provided a platform to test the functionality of fiber optic Bragg grating sensors at cryogenic temperatures. The Y-joint SHM tests validated durability and survivability of the fiber Bragg grating sensors and surface bonding technique through multiple liquid Helium temperature excursions and mechanical load cycles. The fiber optic sensors not only survived the test but showed good agreement with traditional strain gauges. Small strain reading differences between conventional strain gauges and fiber Bragg grating sensors may be attributed to not being co-located exactly next to each other and because an assumed strain-optic coefficient was utilized rather than performing calibration to obtain the exact value. Results from the subscale cryotank tests ${ }^{11}$ show that the strain gauges bonded to the interior of the cryotank often fail. Fiber optics sensors may provide a method to mitigate this problem. The performance of the fiber optic sensors show that they are a viable alternative to strain gauges, especially in harsh or extreme environmental conditions particularly where ignition sources must not be present. This opens the opportunity for bonding these sensors to the inner mold line of cryogenic tanks for structural health monitoring.

\section{ACKNOWLEDGEMENTS}

The authors gratefully acknowledge Dr. Stan DeHaven and Dr. Meng-Chou Wu for drawing the custom optical measurement fibers used for this testing and Dr. Robert Rogowski for outstanding programmatic support, all of the Nondestructive Evaluation Sciences Branch at NASA Langley Research Center in Hampton, VA. The authors also acknowledge outstanding computational support by Hasan T. Abu-Khajeel of Lockheed Martin Space Operations in Hampton, VA, instrumentation attachment by Mark Roth and Tom Winkler of Modern Machine and Tool Company of Hampton, VA, and testing support by Donny Wang of Northrop Grumman Corporation Integrated Systems Sector El Segundo, CA.

\section{REFERENCES}

1. W. H. Prosser, S. G. Allison, S. E. Woodard, R. A. Wincheski, E. G. Cooper, D. C. Price, A. Tessler and J. L. Spangler, "Structural Health Management for Future Aerospace Vehicles," The Second Australian Workshop on Structural Health Monitoring, Monash University Australia, December 16-17, 2004

2. Prosser, W. H., Wu, M-C, Allison, S. G., DeHaven, S. L. and Ghoshal, A., "Structural Health Monitoring Sensor Development at NASA Langley Research Center," Proceedings of the International Conference on Computational \& Experimental Engineering and Sciences (ICCES '03), Corfu, Greece, paper ID 149, July 2529, 2003.

3. B. A. Childers, M. E. Froggatt, S. G. Allison, T.C.Moore, D.A.Hare, C.F.Batten,, D.C.Jegley,"Use of 3000 Bragg grating strain sensors distributed on four eight-meter optical fibers during static load testing of a composite structure," Proceedings, SPIE's 8th Annual International Symposium on Smart Structures and Materials in Newport Beach, California, Vol. 4332, Paper No. 4332-17, March 2001

4. M. E. Froggatt, and W. Bowen, "Optical Time Domain Reflectometry in Optical Fiber with Reflection Delay Time Matched to the Period of the Optical Frequency Modulation," Appl. Opt. , Vol. 37, No. 10, pp. 17311734 (1998).

5. M. E. Froggatt and J. Moore, "Distributed Measurement of Static Strain in an Optical Fiber with Multiple Bragg Gratings at Nominally Equal Wavelengths," Appl. Opt., Vol. 37, No. 10, pp. 1741-1746 (1998).

6. M. E. Frogatt, U.S. patent 5,789,521, "Apparatus and Method for Measuring Strain in Bragg Gratings" (1998). 
7. T. Brown, K. Wood, B. Childers, R. Cano, B. Jensen, and R. Rogowski; "Fiber Optic Sensors for Health Monitoring of Morphing Aircraft," Proceedings of The International Society for Optical Engineering (SPIE), Vol. 3674, pp. 60-71 (1999).

8. L. Melvin, B. Childers, R. Rogowski, W. Prosser, J. Moore, M. Froggatt, S. Allison, M. C. Wu, J. Bly, C. Aude, C. Bouvier, E. Zisk, E. Enright, Z. Cassadaban, R. Reightler, J. Sirkis, I. Tang, T. Peng, R. Wegreich, R. Garbos, W. Mouyos, D. Aibel, P. Bodan, "Integrated Vehicle Health Monitoring (IVHM) for Aerospace Vehicles," presented at the International Workshop on Structural Health Monitoring, Stanford, CA, September 18-20, 1997. In "Structural Health Monitoring Current Status and Perspectives," pp. 705-714, edited by FuKuo Chang, Technomic Publishing Co. Inc., Lancaster, PA, ISBN No. 1-56676-605-2 (1997).

9. M. E. Froggatt, "Distributed Measurement of the Complex Modulation of a Photoinduced Bragg Grating in an Optical Fiber," Appl. Opt., Vol. 35, No. 25, pp. 5162-5164 (1996).

10. A. D. Kersey, M. A. Davis, H. J. Patrick, M. LeBlanc, K. P. Koo, C. G. Askins, M. A. Putnam, E. J. Friebele, "Fiber Grating Sensors," J. of Lightwave Tech., 15(8) (1997).

11. Document No. SLI-03-1038, Cage Code 76823, "Full Scale Tank Structural Health Management (SHM) System Design Second Generation Reusable Launch Vehicle -Airframe," prepared for NASA Marshall Space Flight Center by Northrop Grumman Integrated Systems, One Hornet Way, El Segundo, CA under contract NAS8-01100, May 7, 2004.

12. Document No. SLI-03-1039, Cage Code 76823, "Y-Joint Structural Health Monitoring (SHM) Test Report Second Generation Reusable Launch Vehicle -Airframe," prepared for NASA Marshall Space Flight Center by Northrop Grumman Integrated Systems, One Hornet Way, El Segundo, CA under contract NAS8-01100, May 13, 2004.

13. Winfred S. Kenner, Sid Allison, Tod Palm, Chandu Shah, Stephen McCleskey, Andre Lavoie, Don Enno, Donny Wang, Jim Bohlen and Hasan T. Abu-Khajeel, "Experimental and Analytical Investigation of a Joint Between Liquid Hydrogen Tank and Intertank Structure for a Reusable Launch Vehicle," Proceedings of JANNAF $40^{\text {th }}$ Combustion Subcommittee $/ 28^{\text {th }}$ Airbreathing Propulsion Subcommittee $/ 22^{\text {nd }}$ Propulsion Systems Hazards Subcommittee $/ 4^{\text {th }}$ Modeling and Simulation Subcommittee joint meeting, Charleston SC, June 13-16, 2005.

14. "The Mechanical Strength of Silica Optical Fibers," 3M Silica Optical Fibers Application Note (1995).

15. "The Mechanical and Optical Reliability of Fiber Bragg Gratings," 3M Fiber Bragg Gratings Application Note (1996).

16. NASA/TM-2004-213017 "Suggested Procedures for Installing Strain Gauges on Langley Research Center Wind Tunnel Balances, Custom Force Measuring Transducers, Metallic and Composite Test Articles," Thomas C. Moore Sr., NASA Langley Research Center, Hampton, VA January 5, 2004

17. Sidney G. Allison, Robert L. Fox, Mark E. Froggatt, Brooks A. Childers, "Novel Piezoelectric actuators for tuning an optical fiber Bragg grating," Optical Engineering 41(10) 2448-2455 (October 2002).

18. W. W. Morey, J. R. Dunphy and G. Meltz, "Multiple Fiber Bragg Grating Sensors," Proceedings of the International; Society of Optical Engineering (SPIE), Vol. 1586, pp. 216-224 (1991).

The use of trademarks or names of manufacturers in the report is for accurate reporting and does not constitute an official endorsement, either expressed or implied, of such products or manufacturers by the National Aeronautics and Space Administration. 